\title{
Desenvolvimento tecnológico, estilo televisivo e telenovelas: possíveis reconfigurações do gênero na produção de Gabriela ${ }^{1}$
}

Simone Maria Rocha

Resumo: As relações entre desenvolvimento tecnológico, inovações estilísticas e possíveis reconfigurações no gênero das telenovelas são analisadas através de trechos exibidos no primeiro capítulo da novela Gabriela, que dramatizaram sua travessia do sertão até Ilhéus num elaborado trabalho de composição visual em detrimento do diálogo como condutor da trama. O objetivo é mostrar que mudanças naquelas relações podem sugerir mudanças nas estratégias de comunicabilidade do referido gênero.

Palavras chave: estilo televisivo, gênero televisivo, tecnologia, telenovela Gabriela.

Abstract: Technological development, television style and telenovelas: possible genre reconfigurations in the production of Gabriela - The relations among technological development, stylistic innovations and possible reconfigurations in telenovela's genre will be analysed through excerpts of the first episode from the telenovela Gabriela, which portray the travelling from the hinterland to Ilhéus, in an elaborate work of visual composition at the expense of dialogue as the plot conductor. The goal is showing that amendments in those relations can suggest changes in the communicability strategies that characterize the referred genre.

Key words: television style; television genre; technology; telenovela Gabriela.

O objetivo deste texto é explorar, através da análise do estilo, o modo como o drama da travessia do sertão até a cidade de Ilhéus de Gabriela (Rede Globo, 2012) foi encenado com base em composição visual mais elaborada, iluminação que fugiu

1 Agradeço ao CNPq e à FAPEMIG o apoio financeiro. 
ao padrão transparente, planos abertos e escassez de diálogo, diferenciando-se do modo como esses elementos são usualmente apresentados nesse gênero.

Sempre houve inovações na telenovela brasileira (AIRES, 2013b; LOPES, 2004; MOTTER, 2004), sobretudo no que diz respeito à narrativa, à temática e à intertextualidade, o que indica que tal aspecto faz parte do gênero. Contudo, sobre a noção de inovação na televisão, ainda não contamos com uma literatura dedicada de modo específico ao tema. Valho-me das ideias de Jean-Pierre Esquenazi (2011) que, ao estudar o fenômeno tanto social quanto midiático das séries televisivas, buscou compreender inovação como mudanças provocadas no sistema de produção e nos modos de escrita televisiva. Esquenazi parte dos estudos de Edgard Morin, que acredita que a insensibilidade intelectual impediu que os críticos fossem capazes de reconhecer que a cultura de massa precisa de inovação como imperativo de sobrevivência.

Neste texto procuro voltar minha atenção para o aumento da qualidade técnica de produção de imagem e som, sobretudo após a implementação da televisão digital no Brasil e a popularização de aparelhos com alta definição (HD), com dois objetivos. O primeiro é observar em que medida tal fato permitiu inovações no estilo televisivo. O segundo é captar se tais inovações possibilitam pensar em reconfigurações das estratégias de comunicabilidade que caracterizam o gênero das telenovelas.

\section{Elementos para uma estilística televisiva e suas aproximações com o gênero}

Parto do referencial teórico exposto nas obras de Jeremy Butler (2009, 2010), que conceitua o estilo como qualquer padrão técnico de som-imagem que sirva a uma função dentro do texto televisivo. Essa definição tem uma dupla importância para os estudos do estilo em televisão: 1) rejeita concepções que o consideram como a marca da genialidade individual em um texto ou como um floreio decorativo de camadas acima da narrativa (embora alguns estilos sejam decorativos); 2) possibilita concluir que todos os textos televisivos contêm estilo. Para Butler, "estilo é a sua estrutura, a sua superfície, a rede que mantém juntos seus significantes e através do qual os seus significados são comunicados" (2010, p. 15). Ao desenvolver o tema, voltando-se especificamente para a televisão, Butler inspira-se em David Bordwell, para quem estilo

é a textura tangível de um filme, a superfície perceptual que nós encontramos enquanto vemos e ouvimos, e esta superfície é o nosso ponto de partida na movimentação da trama, do tema e do sentimento - tudo o que importa para nós (BORDWELL, 2008, p.32). 
O estilo televisivo vem sendo construído levando-se em consideração aspectos materiais e imateriais do dispositivo². Numa primeira caracterização, a TV possuía telas de tamanho reduzido, pouca exploração da profundidade de campo, imagem de baixa qualidade, escala de planos reduzida, baseada em planos médios, primeiros planos e close-ups. O meio compensava a simplicidade de suas imagens com as técnicas de corte rápido. O uso de várias câmeras e a possibilidade de alternância entre elas produzia um estilo específico: a fragmentação dos eventos mantendo-se, ao mesmo tempo, sua continuidade. A falta de variação de cores e a precariedade da captação de som também contribuíram para a criação de convenções estéticas como, por exemplo, os diálogos construídos na clássica montagem plano/contraplano.

Para Jeremy Butler (2009) os vínculos econômicos, culturais e tecnológicos mantidos entreTV e rádio caracterizaram uma estética televisiva em grande medida dependente do som. Por isso, a experiência de assistir televisão era igualmente uma experiência de ouvir televisão.

Nesse sentido, as condições de recepção exerceram influências importantes no regime de representação desenvolvido pela TV. O medium fazia (e ainda faz) parte do ambiente doméstico e exige um baixo grau de concentração do telespectador. Uma forte relação com o áudio permitia que as pessoas se envolvessem em atividades simultâneas como, por exemplo, fazer o jantar, o dever de casa, passar as roupas, etc.

Para John Ellis (1992), o regime de representação característico da televisão partiu do pressuposto de que o papel desempenhado pelo som é extremamente importante e que o olhar destinado à televisão é sempre desatento e fugaz. Isso pode redundar numa complexa relação entre som e imagem baseada em dois elementos: a ênfase no som, como garantia da continuidade da atenção, e a carência de detalhe, que reduz o valor de informação da imagem, produzindo uma estética que privilegia o corte rápido. Já os planos em close-ups produzem rostos que se aproximam do tamanho normal, gerando uma sensação de igualdade e de intimidade em quem assiste. Dessa relação, entre som e imagem, derivam-se os estilos. No caso dos produtos ficcionais, a maioria dos gêneros adota o direcionamento indireto e sempre dependeu fortemente do diálogo para conduzir sua narrativa. Esse é um esquema bem estabelecido no meio ${ }^{3}$. Música e efeitos sonoros também sustentam uma das principais funções do estilo televisivo: chamar e manter a atenção do telespectador.

Acredito que esses elementos, aliados aos atributos tecnológicos e estilísticos, às

2 Não desconheço que as análises de cinema e televisão contam com tradições teóricas distintas e até certo ponto divergentes, mas defendo o argumento segundo o qual a análise estilística da TV não consiste apenas em adotar diretamente as técnicas do cinema. O que seus críticos fazem é adotar os conceitos desenvolvidos nos estudos fílmicos para analisar os elementos do estilo televisivo. Assim, a visão geral das principais técnicas desse estilo - encenação, trabalho de câmera, edição, trilha, elementos gráficos - emprega o vocabulário estabelecido pelos pesquisadores de cinema para analisar filmes, mas destaca os modos particulares através dos quais a televisão usa o estilo de uma maneira distinta do cinema.

3 Sobre a noção de esquema cf. BORDWELL, 2008, p.322. 
condições de produção e de recepção, contribuem para a configuração dos diferentes gêneros das narrativas ficcionais. Jesús Martín-Barbero considera gênero como mediação, uma estratégia de comunicabilidade que opera entre a lógica do sistema produtivo e a lógica dos usos:

[...] No sentido em que estamos trabalhando, um gênero não é algo que ocorra no texto, mas sim pelo texto, pois é menos questão de estrutura e combinatórias do que de competência [...] A consideração dos gêneros como fato puramente 'literário' - não cultural - e, por outro lado, sua redução a receita de fabricação ou etiqueta de classificação nos têm impedido de compreender sua verdadeira função e sua pertinência metodológica: chave para análise dos textos massivos e, em especial, dos televisivos (MARTín-BARBERO, 2001, p. 304).

Gênero é o lugar do cruzamento e da realização. Martín-Barbero o vê como uma forma abstrata que possui uma dimensão pragmática de reconhecimento, "falo de gênero como um lugar exterior à 'obra', a partir de onde o sentido da narrativa é produzido e consumido, ou seja, lido e compreendido" (MARTíN-BARBERO, 2001, p. 189). Ao abordá-lo, Itania Gomes ressaltou sua relevância compreendendo-o como um lugar central para entrever as relações entre comunicação, cultura e política: "se o gênero é uma estratégia de comunicabilidade que articula lógicas de produção com competências de recepção e matrizes culturais com formatos industriais, ele não pode estar em outro lugar" (GOMES, 2011, p.125).

Conquanto o gênero televisivo diga respeito às estratégias de comunicabilidade é preciso ressaltar que ele só é exprimível mediante uma materialidade simbólica, um arranjo específico de som e imagem que ganha concretude sob a lógica do formato. Do ponto de vista da produção, o formato conforma e materializa a representação audiovisual funcionando como um instrumento que confere padrões e normas aos programas televisuais; é ele quem estabiliza os elementos que dão forma a uma emissão (REZENDE, 2012). Essa discussão indica a estabilidade como um fator importante na relação que se pretende estabelecer com a audiência. Em Gabriela, essa relação não foi diferente, ou seja, o diálogo foi o recurso estilístico mais adotado para retratar a maioria das tramas.

Contudo, uma novidade se fez notar: o evento da travessia do sertão até Ilhéus deu a ver uma diferente configuração na relação som-imagem posto que o drama contado sustentou-se sobremaneira na composição dos elementos visuais das sequências selecionadas.

Meu argumento é o de que Gabriela inovou a partir das possibilidades técnicas permitidas pelo suporte. Diante disso, nas próximas seções, discutirei sobre as articulações entre desenvolvimento tecnológico, novas composições estilíticas e possíveis reconfigurações no gênero.

\section{Do desenvolvimento tecnológico, das novas possibilidades estilísticas na TV...}

Em setembro de 2013, ao receber o prêmio Emmy de melhor série dramática, o diretor de fotografia do programa americano Breaking Bad, Michael Slovis, afirmou que 
"o verdadeiro segredo para o sucesso da série foi a tecnologia"4. Televisores de tela plana ficaram mais acessíveis nos últimos anos fazendo com que a tecnologia HD se tornasse a norma. Para Slovis, sua popularização conferiu mais liberdade no processo de produção e permitiu à equipe contar a história, explorando um tipo de visualidade que fugia ao estilo close-up pós close-up.

A transição do sinal analógico para o digital, associado à produção de equipamentos específicos para a captação High Definition (HD) e à comercialização dos televisores HD, trouxe diversas mudanças na forma de se produzir e se consumir TV. Dentre elas, podemos destacar a ratio da HDTV de 16:9, enquanto a televisão no modelo standard definition (SD) apresentava ratio de 4:3 e o trabalho de direção de arte, uma vez que os aparelhos em HD, ao possuírem maior nitidez e definição, possibilitam a visualização de detalhes, fazendo com que cenógrafos, figurinistas e maquiadores se atentem para construções mais precisas, para que agora tudo seja flagrado pela alta definição. Sendo assim, "detalhes que antes eram 'suportáveis' tornam-se aparentes na alta definição, mesmo nos planos intermediários ou de fundo" ${ }^{\prime \prime}$. As cores também tornam-se mais vibrantes e é possível perceber melhor a diferenciação entre os mais variados tons. Quanto a iluminação, no HD é possível obter uma maior relação de contraste, o que proporciona transições de baixas luzes.

A tecnologia HD também demanda câmeras específicas, como o uso de Prime Lenses, que possuem um campo focal fixo, uma maior profundidade de modulação e uma menor profundidade de campo. Todos esses aspectos técnicos refletem em uma reconfiguração da estética das produções televisivas, apresentando-nos produtos trabalhados visualmente de forma diferenciada, com mais detalhes em cena (fig. 01).

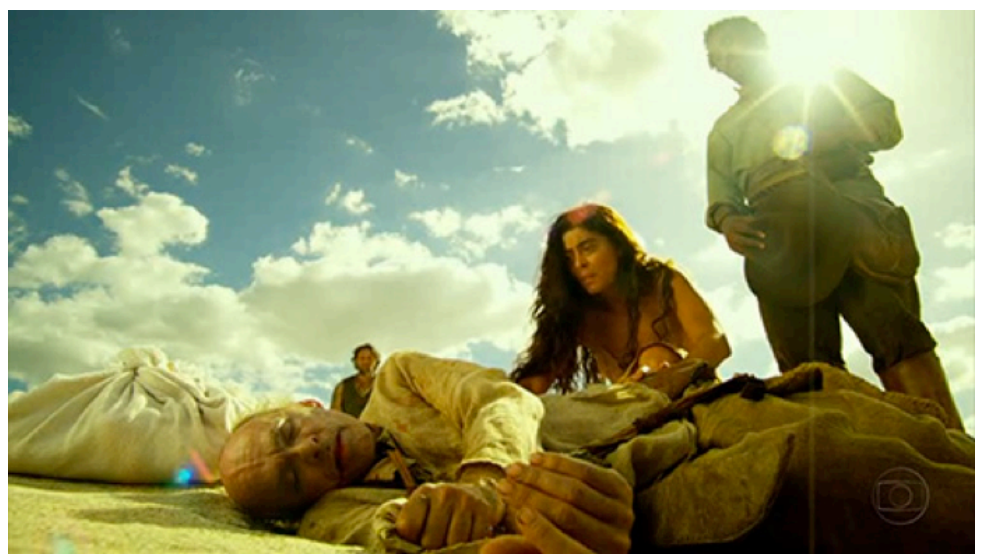

Fig. 1.Cena em que o tio de Gabriela é encontrado morto. Notamos todos os personagens definidos nitidamente em diferentes planos, assemelhando-se a uma pintura. A relação de latitude possibilitada pelas novas câmeras HD e seus acessórios permitem composições como esta na televisão.

4 Disponível em <http://www.techspot.com/news/54172-breaking-bad-secret-to-success-is-in-the-technologyhd-dvr-netflix.html>, acesso em 05 nov. de 2013.

5 Disponível em <http://issuu.com/telaviva/docs/pdf_123q6?e=1344148/3988471>, acesso em 02 dez. de 2013. 
Em 2007, ano em que o sinal de televisão digital e em HD foi implementado no Brasil, identificamos tais mudanças. As matérias "O que muda com a alta definição" ${ }^{\prime 6}$, do portal Folha Online, e "TV digital em alta definição revela detalhes e defeitos das produções" ${ }^{7}$, do portal IDNow, evidenciam por parte dos jornalistas tanto essa preocupação com o acabamento na direção de arte quanto a expectativa por uma televisão com maior definição, nitidez e qualidade estética que se assemelharia às produções cinematográficas. Em 2011, a adoção dessa inovação tecnológica nos trouxe o primeiro resultado, que chamou atenção tanto da crítica quanto do público. A telenovela Cordel Encantado (TV Globo, 2011) apresentou uma imagem que se diferenciava e se destacava das demais produções da época e que foi muito comparada ao cinema, por mostrar composições visuais mais elaboradas tanto na fotografia quanto na direção de arte (figurino, cenário e maquiagem).

O destaque para a direção de fotografia conduzida por Fred Rangel foi evidente. O fotógrafo recebeu o Prêmio de Reconhecimento CGP 2011 na categoria que atua e, em entrevista a revista Luz e Cena, revelou como a reconfiguração nesse campo da produção audiovisual é consequência do desenvolvimento tecnológico:

As câmeras de vídeo vêm evoluindo em resolução, sensibilidade e latitude. O sensor Full 35, que é do tamanho de um negativo de $35 \mathrm{~mm}$, trouxe para o vídeo a mesma relação ótica das câmeras de cinema. Buscamos na TV a simbiose entre a qualidade mostrada no cinema e a velocidade empregada pela TV. A alta definição nos proporciona essa possibilidade de estreitar essa diferença. Na TV, tivemos que aprimorar nossas qualidades nos acabamentos cenográficos, caracterização e figurinos. E a luz é fator primordial nessa evolução, uma vez que, com definição abundante, temos que ter mais cuidado em fotografar.

De alguma forma, o grande público percebeu isso, a ponto de dizer que a novela parecia cinema. Mexemos no setup das câmeras e, pela primeira vez na teledramaturgia da TV Globo, gravamos em 24 quadros. Outro fator importante foi a luz no contra-eixo, que permitiu o contraste e salientar apenas o que era necessário dentro de uma cena. ${ }^{8}$

Este trabalho de Rangel pôde ser visto novamente em Avenida Brasil (Rede Globo, $2012)^{9}$, e recentemente na telenovela Joia Rara (Rede Globo, 2013) ${ }^{10}$, chamando a atenção da crítica e do público para aspectos da composição visual.

6 Disponível em: <http://www1.folha.uol.com.br/fsp/especial/fj0212200704.htm> Acesso em 02 de dez. de 2013.

7 Disponível em: <http://idgnow.uol.com.br/mobilidade/2007/11/26/idgnoticia.2007-11-26.6907384618> Acesso em 02 de dez. de 2013.

8 Disponível em: http://www.musitec.com.br/luzecena/revista_artigo.asp?revistalD=2\&edicaolD=148\&nav ID=4002. Revista Luz e Cena. Edição \#148, novembro de 2011.

9 "Fotografia de 'Avenida Brasil' é um dos elementos do sucesso da novela." Disponível em: <http://blog.jovempan. uol.com.br/parabolica/fotografia-de-avenida-brasil-e-um-dos-elementos-do-sucesso-da-novela/> Acesso em 02 de dez. 2013.

10 "Apesar da estética sofisticada, 'Joia Rara' não passa de um bom folhetim" Disponível em: <http:// nilsonxavier.blogosfera.uol.com.br/2013/11/22/apesar-da-estetica-sofisticada-joia-rara-nao-passa-de-um-bomfolhetim/>Acesso em 02 de dez. de 2013. 
Esse breve retrospecto da implementação da TV digital no Brasil e de algumas produções televisivas dos últimos anos é útil para evidenciar como o desenvolvimento tecnológico ofereceu uma imagem mais precisa, além de ampliar os recursos de criação, produção e edição. A ênfase em tal aspecto não supõe um pensamento tecnologicamente determinista, isolado de fatores sociais, econômicos, culturais e políticos. A preponderância da tecnologia se justifica pela ausência significativa dessa abordagem na literatura disponível, apesar de sua relevância para a televisão que assistimos atualmente.

Segundo Renata Rezende,

Notamos que à medida que as possibilidades de produção e manipulação de imagens e sons se desenvolvem não apenas em termos técnicos (com o uso de câmeras que geram imagens com melhor resolução e ilhas de edição que proporcionam inúmeros efeitos) mas também estéticos, há um investimento em narrativas audiovisuais cada vez mais sensórias, na tentativa de conduzir o espectador para dentro do mundo-tela (REZENDE, 2012, p.13).

É isso que vislumbro nas sequências que dramatizaram a travessia de Gabriela ${ }^{11}$ : um tipo de composição visual que captou o telespectador para dentro da imagem, enfatizou a tridimensionalidade, explorou a profundidade do plano e inovou em composições estilísticas. Ademais, sustentou a narrativa da travessia feita pelos personagens-retirantes a partir de suas dificuldades, seus obstáculos e seu sofrimento ${ }^{12}$. Roberto Talma e Mauro Mendonça Filho, que já haviam trabalhado juntos na antecessora do horário, O Astro, assinaram a direção geral e Sergio Marini a direção de fotografia.

\section{As razões para partir}

A travessia tem início quando o tio idoso de Gabriela, enquadrado em primeiro plano, explica a outro morador do sertão o motivo de sua partida e o aconselha a fazer o mesmo, pois ali só a morte esperava por eles. A narrativa é bem pausada e, embora nesse primeiro trecho a presença do diálogo seja constante e ressalte a dimensão visual, a forma como ele foi introduzido diverge dos modos mais comuns pelos quais o diálogo conduz uma narrativa de telenovela. Tal trecho é exibido em planos fixos de imagens emblemáticas

11 Ainda que partamos do conjunto das sequências exibidas no primeiro capítulo, não seria possível na extensão desse artigo, descrever e analisar todas elas. Renato Pucci Jr. esclarece que "não é necessário analisar a obra inteira - diz um princípio da metodologia analítica aplicável em relação ao cinema e, por excelentes razões, aos estudos de televisão. Mesmo que a análise completa fosse possível no caso de um único filme (o que não é, além de que seria um trabalho estafante e inútil), em relação à telenovela o empreendimento seria absurdo devido às gigantescas dimensões do objeto. Para uma análise proveitosa deve bastar a análise de pontos nodais, aqueles que podem conter os elementos necessários para que se atinja o objetivo da investigação" cf. PUCCI JR., 2014, p. 682.

12 A questão de um imaginário compartilhado acerca do sertão foi objeto de discussão do trabalho "Inovações estéticas na TV: a travessia sertão-Ilhéus de Gabriela", apresentado na ST Televisão - formas audiovisuais de ficção e documentário, no XVII Encontro Anual da SOCINE, em Florianópolis, Outubro de 2013. 
da seca no sertão: sol dilacerante, árvores secas e mortas, ossadas, clima semiárido. A conversa final entre esses personagens é vista sob o ponto de vista do espectador, pois ambos caminham de costas para a câmera num plano sequencia de 12 segundos.

Em seguida, Gabriela nos é apresentada pegando água num poço praticamente seco e juntando seus poucos pertences, a mando do tio, para iniciarem a travessia. Na sequência, os dois andam pelo sertão seco, empoeirado, sob um forte sol. O tio vai na frente e Gabriela segue atrás puxando um jumento. Até esse momento quase nada é dito. Ficam apenas a sucessão de imagens em cores fortes, em tons amarelados, simbolizando os raios do sol. Há também detalhes do solo quebradiço, das árvores finas, dos gravetos secos, do sol no rosto e de cruzes fincadas no chão.

No trecho final, a noite cai, Gabriela e o tio (já bastante fragilizado e com tosse forte) param para comer e descansar. Eles improvisam um assado quando, de repente, ouvem um barulho vindo do escuro. De lá surgem dois homens famintos: Fagundes e Clemente. Quando o primeiro reclama a fome, o tio responde ríspido: "aqui só tem pra nossa viagem". Nesse momento uma tensão se estabelece, expressada pelo olhar desconfiado de Gabriela, e reforçada pela trilha sonora. Clemente acalma os ânimos e ambos se sentam afastados de Gabriela e do tio. Uma trilha baseada em cordas de violão serve de tema para as trocas de olhares numa sequência entremeada de close-ups entre os personagens, principalmente dos homens famintos (figs. 2-5) a salivar pelo assado (fig. 6). Chamam a atenção o uso de planos detalhes nos olhares tensos dos personagens em cena e a luz baixa, que ajudam a expressar a tensão de um momento no qual um conflito está prestes a acontecer. Não há diálogo. Apenas as trocas de olhares e os planos detalhes do assado e das armas expressam o sentido que a narrativa pretende construir. E é esse uso específico dos recursos de enquadramento, iluminação e trilha que procuramos evidenciar aqui, bem como o efeito de sentido que produzem numa situação concreta.
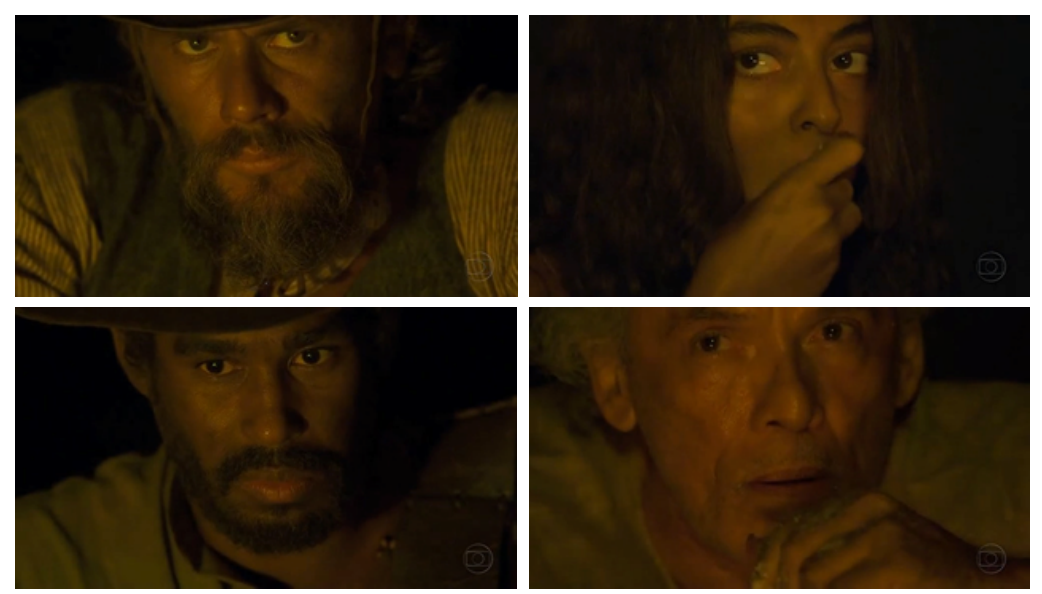

Figs. 2,3,4 e 5. Close-up Clemente, Gabriela, Fagundes e Tio. 


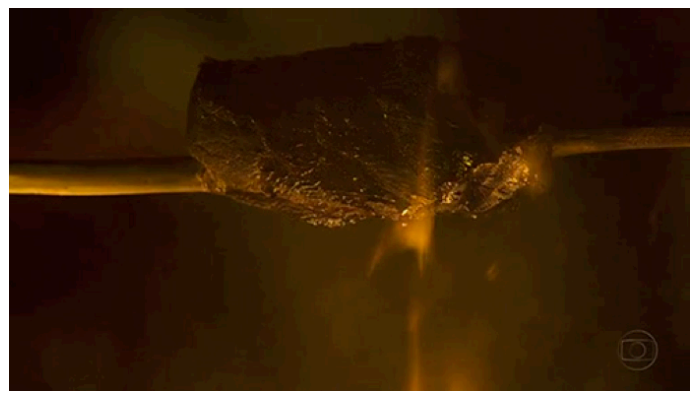

Fig. 6. Plano detalhe da carne

Nas cenas diurnas, quando os retirantes estão em trânsito, o que vemos na tela é uma sequência de planos gerais e planos conjuntos com personagens diminutos aos olhos do espectador. É a ambiência do sertão que se impõe sobre eles, como um verdadeiro obstáculo a ser vencido. Daí a nitidez do fundo natural, a presença física da terra. São planos que nos mostram uma paisagem árida, coberta por pedras, em cuja imagem predominam tons terrosos que simbolizam a secura do lugar. Nessas passagens a trilha é como a de um clamor.

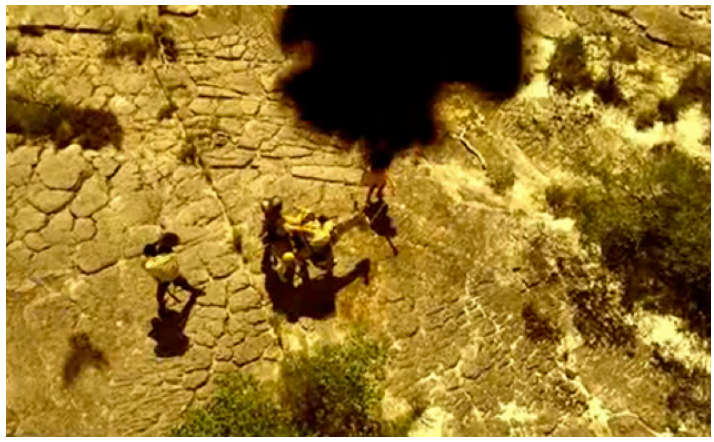

Fig. 7.Travessia dos retirantes em Gabriela

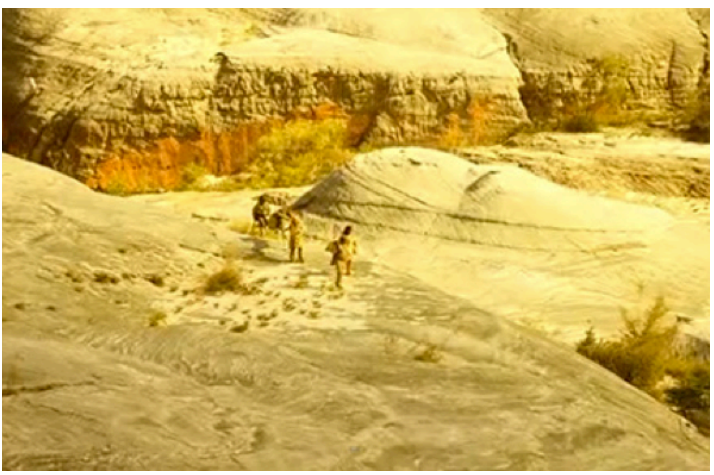

Fig. 8. A força do cenário no drama da travessia 
A análise estilística indica que, nas figuras de 7 a 9, a composição visual contou com planos mais abertos, sequências mais longas, movimentação de câmera menos intensa, que pretendeu evidenciar a pequenez dos retirantes diante da magnitude do sertão e as composições visuais, expondo essas personagens sempre castigadas pelo sol e pela seca. Nesse sentido, o cenário se impõe sobre os viajantes e atua como a figuração do desafio e do infortúnio vividos pelos retirantes que se arriscaram a atravessar o sertão ${ }^{13}$. Diante da ausência de diálogo, a trilha sonora baseada em cordas de violão procurou despertar sensações de angústia e sofrimento.

Nas figuras 7 e 8 a luz natural foi um dos componentes estilísticos explorados e a direção de fotografia não teve receio de jogar com as sombras, de transitar entre o claro e o escuro, de colocar em cena os elementos com aparência semelhante à vida real para provocar-nos alguma identificação com o drama encenado.

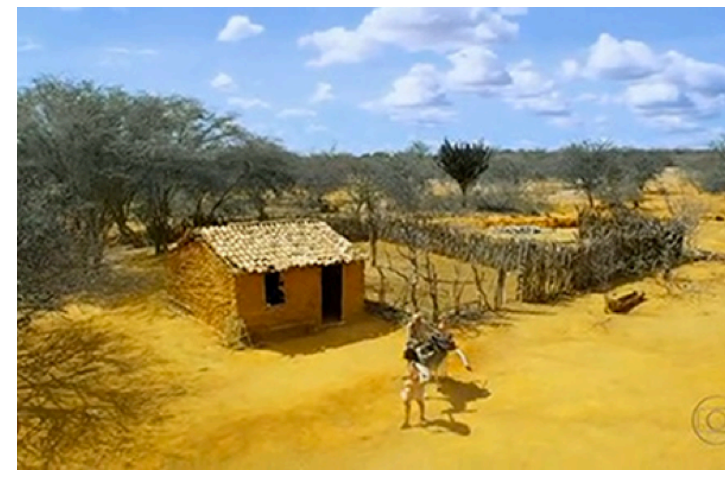

Fig.9. A força do cenário no drama da travessia

Tecnicamente, a amplitude dos planos e a dimensão diminuta dos personagens da travessia foram possibilitados pela disseminação das já mencionadas tecnologias de HD. Outra inovação adotada em Gabriela foi a utilização de um drone (veículo não tripulado) adaptado a uma câmera (fig. 10) ${ }^{14}$. Esse equipamento é operado por controle remoto e oferece mais possibilidades para o trabalho dos diretores. A produção alega que essa é a primeira vez que um aparelho desse tipo é usado na teledramaturgia brasileira, e foi possível graças ao desenvolvimento desse aparato tecnológico e de câmeras mais leves. No caso em análise tal recurso permitiu a realização in loco de enquadramentos e movimentos que fortaleceram

13 Evidentemente que não negligencio produções ficcionais seriadas como Pantanal, Renascer, Rei do Gado, anteriores à tecnologia digital, que usaram dos planos gerais, abertos, em que o ambiente natural tinha força de personagem. A questão que este texto procura evidenciar volta-se para dois aspectos: 1) a questão estilística apontada diz da relação diferenciada entre diálogo e imagem - com notória preponderância para o primeiro no evento em questão; 2) a travessia de Gabriela foi encenada apenas no primeiro capítulo, sendo que não houve nenhuma recapitulação de tal drama no decorrer da telenovela; aspectos que abordarei um pouco mais adiante.

14 Disponível em: <http://www.ofuxico.com.br/noticias-sobre-famosos/objeto-estranho-sobrevoa-gravacoes-degabriela-no-sertao/2012/04/30-138430.html> Acesso em 12 de dez. de 2013. 
a dimensão dramática que os realizadores pretendiam configurar: quão os personagens resultaram pequenos e frágeis diante da força e da vastidão do sertão a ser atravessado.

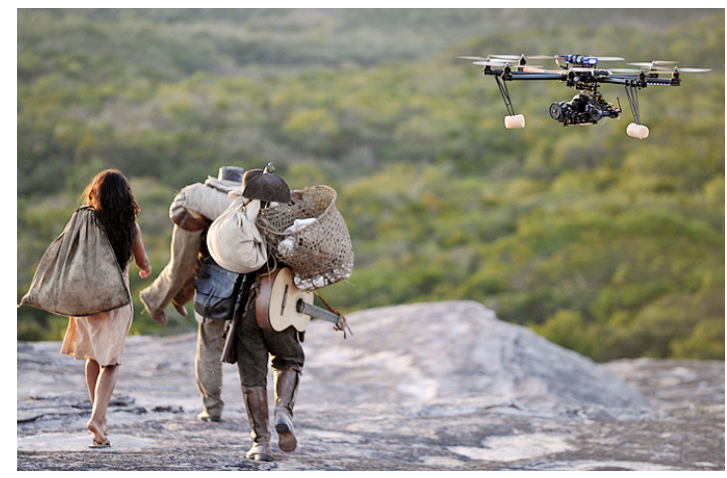

Fig. 10. Câmera montada em um drone do tipo octocopter.

Na versão de 1975, a travessia mostrou uma personagem viajando por um sertão empoeirado e repleto de cactos, em tomadas mais fechadas e claustrofóbicas. Em 2012, as sequências dessa viagem investiram em qualidade visual, mostrando a peregrinação através de cenas bem elaboradas, uma fotografia bem trabalhada, cenário com força de personagem e planos gerais suntuosos (fig. 11).

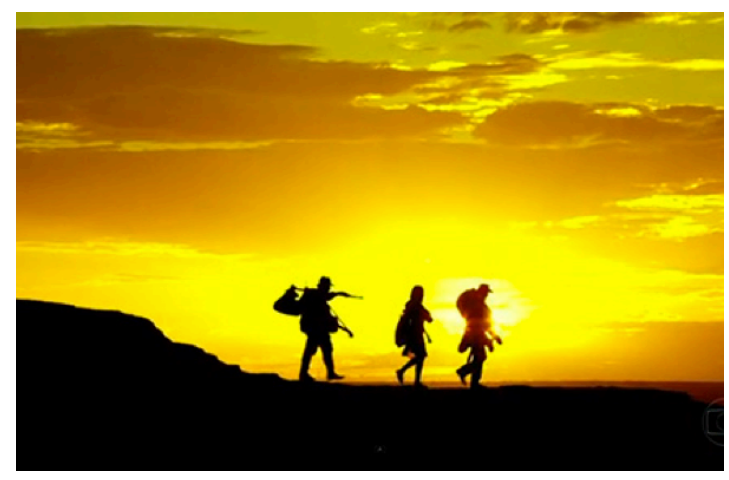

Fig.11. Plano geral de Gabriela

Assim, foi possível evidenciar os modos pelos quais convenções sociais atinentes à percepção e ao reconhecimento se concretizam nos códigos tecnológicos, oportunizando novas estratégias e relações tanto de produção quanto de recepção. 


\section{... e das possíveis reconfigurações no gênero}

Dentre as dimensões que configuram o gênero da telenovela destaco três: sua forma e estrutura enquanto um objeto de comunicação, relacionado ao meio através do qual se realiza; a interpenetração entre ficção e realidade num processo de interação com a cultura e o cotidiano; e a dimensão da realização, da produção e das condições de recepção, que também estão articuladas ao medium. Ainda que todas sejam relevantes na constituição do gênero, interessa-me explorar as características estilísticas, notadamente os elementos visuais.

Considero relevante, antes disso, apresentar algumas características específicas do objeto desta análise. Gabriela faz parte da proposta de um novo formato, conhecido como "novela das onze", cuja duração gira em torno de 75 capítulos. Outra característica relevante diz respeito a redundância da narrativa, ou seja, aos recursos de recapitulação necessários ao acompanhamento da trama tendo em vista os hábitos relativos ao consumo de televisão. Para Kristin Thompson (2000) é preciso oferecer à audiência possibilidades de compreensão e seguimento de uma narrativa com múltiplos enredos. Cannito (2010) afirma que as redundâncias ocorrem em virtude da serialidade e da montagem da grade de programação. Retomando Gabriela, o drama da travessia não foi recapitulado nos capítulos subsequentes, de modo que o telespectador pudesse ser situado em relação à origem da jovem. O evento foi encenado em quatro sequências do primeiro capítulo e nada mais. Os autores indicam que redundar, além de atentar-se para os hábitos de consumo, possui, também uma dimensão econômica, pois significa correr menores riscos dada a estabilidade que esses processos conferem às atividades de produção. Nesse caso, redundância e repetição são ferramentas que remetem primeiramente às lógicas de produção.

Outra característica que julgo central para a indagação deste artigo diz respeito ao lugar do diálogo como artefato do produto. Lima, Motter e Malcher (2000) alegam que é próprio da telenovela basear-se no diálogo. É possível apontar aqui a herança do rádio, mas é igualmente importante retomar o que já foi apontado em seção anterior, tanto no que diz respeito às condições de recepção quanto às condições técnicas da televisão, que ajudaram a configurar seu regime de visibilidade. Em Gabriela, o drama da travessia primou pela encenação, pelo jogo de cenário e personagem que priorizou a visualidade e secundarizou o diálogo.

Ainda que não seja uma unanimidade, nem mesmo em Gabriela, a imagem ampliou-se. Adquiriu mais variação de tom, de luz; mais nuances. Está falando por si só. Está capturando o telespectador para dentro da tela. Não está se vendo traduzida através da sua verbalização e surge como elemento que pode se tornar visível por sua própria força. E o desenvolvimento tecnológico deve somar-se às razões que tornou isso possível.

Voltando à questão deste texto, em que medida uma produção com sequências que inovaram na fragmentação, na redundância e na forma de inserção do diálogo, 
dando ênfase às composições visuais para contar/mostrar um dos dramas de sua história, pode sugerir reconfigurações no gênero?

Ao dispor de uma televisão em HD, o público pode demandar por produtos que atendam à essas especificações. Essas novas composições visuais presentes na televisão ao mesmo tempo que atraem, exigem mais do nosso olhar. Nelas, não basta ouvir para entender. É necessário estarmos atentos ao que nos é mostrado. Por um lado, esse tipo de composição agrega valor ao produto televisivo e faz o espectador desfrutar de uma imagem rica e construída de forma mais elaborada, revelando elementos que antes eram imperceptíveis. Por outro lado, requer um maior engajamento na atividade de assistência e uma maior concentração, diminuindo a possibilidade de dedicação às atividades paralelas, uma vez que a imagem coloca-se como uma narradora de determinada trama. Isso pode gerar novas expectativas em relação ao gênero e pode reorganizar a atividade de recepção. O diálogo abre espaço para articular-se a outros elementos, como fotografia e direção de arte. Essa articulação foi ressaltada por Fred Rangel em relação ao seu trabalho em Cordel Encantado: "Fico muito feliz com o reconhecimento da crítica, dos colegas e, principalmente, do público que, de alguma forma, entendeu que a fotografia ajuda a contar uma história"15.

\section{Considerações finais}

Não tenho a pretensão de afirmar que inovações em uma telenovela podem reconfigurar o gênero. No caso em análise, meu intuito foi o de evidenciar uma nova articulação entre som e imagem que pode indicar novas relações entre a telenovela e seu público. De todo modo, embora tenha vislumbrado essa mudança específica em Gabriela, no que diz respeito às demais inovações na visualidade, cabe ressaltar os caminhos abertos por algumas antecessoras. Ou seja, essas mudanças não são flagradas somente em Gabriela. Alguns autores já vêm apontando essa tendência em outras produções como Avenida Brasil (PUCCI JR, 2014) e Cordel Encantado (AIRES, 2013b). No caso da primeira, Pucci Jr analisa as inovações estilísticas empreendidas no folhetim como planos diferenciados, iluminação contrastada e escura, quebras de eixo e conclui que "Avenida Brasil opera de forma bem sucedida (...) com esquemas compositivos nada comuns" (2013, p. 13).

Ressalvo que inovações fazem parte da história da telenovela, mas é preciso reconhecer que algumas delas têm feito a diferença no que tange à composição visual e que isso pode vir a estabelecer novas relações de engajamento por parte da audiência e levar a mudanças num gênero já tão estabelecido em nossa televisão.

E o desenvolvimento tecnológico contribui para as mudanças neste panorama. Novos testes de captação e reprodução de conteúdo em UHDTV (Ultra High Definition

15 Disponível em: http://tvg.globo.com/programas/melhores-do-ano-cgp/Tudo-sobre-o-premio/2012/ noticia/2013/10/veja-depoimentos-de-vencedores-do-premio-de-reconhecimento-cgp-2011.html. Acesso em 02 de dez. de 2013. 
Television), tecnologia conhecida como 8K, estão sendo realizados em parceria com a NHK, TV pública do Japão. O UHD entrega resolução 16 vezes maior que o Full HD e trabalha com 22.2 canais de áudio, proporcionando aumento na sensação de imersão para o telespectador e permitindo-Ihe maior proximidade com o aparelho ${ }^{16}$. É cedo para apontar modificações daí advindas mas, se recuperarmos o argumento de Butler, para quem o estilo existe na interseção de padrões econômicos, tecnológicos e códigos semióticos/ estéticos, é preciso considerar o fato de que qualquer aspecto que interfira na qualidade da produção e exibição da televisão poderá implicar em inovações estilísticas que exigirão investimento e compreensão de seus desdobramentos em termos de incremento da imagem e da composição diferenciada do audiovisual na produção para este medium. Tal fato se coloca como um desafio àqueles que se dedicam a compreender a importância dos produtos e dos discursos televisivos na contemporaneidade.

Simone Maria Rocha é doutora em Comunicação e Cultura pela UFRJ com pós-doutorado pela UFMG. É professora Associada do Programa de Pós-Graduação em Comunicação Social da UFMG e coordenadora do Grupo de Pesquisa em Comunicação, Mídia e Cultura (COMCULT).

smarocha@ig.com.br

\section{Referências}

AIRES, A. B. Lógicas de Inovação da telenovela: Descontinuidades e Rupturas. Anais - DT 4 Comunicação Audiovisual do XVIII Intercom Região Sudeste, Bauru/SP, 2013a.

. Estratégias de renovação da telenovela: a produção de uma estética da diferença em Cordel Encantado. São Paulo: dissertação de Mestrado apresentada ao PPGCOM/ESPM, 2013b.

BORDWELL, D. Figuras traçadas na luz: a encenação no cinema. Campinas, Papirus, 2008.

BUTLER, J. Televison Style. New York \& London: Routledge, 2010.

. Television: critical methods and applications. 3a. ed. New York \& London: Routledge, 2009.

CANNITO, N. A televisão na era digital: interatividade, convergência e novos modelos de negócio. SP: Summus, 2010.

ESQUENAZI, J.P. As series televisivas. Coimbra: Texto \& Grafia, 2011.

LIMA, S. M. C; MOTTER, M. L.; MALCHER, M. A. A telenovela e o Brasil: Relatos de uma experiência acadêmica. Revista Brasileira de Ciências da Comunicação, vol. XXIII, no 1, 2000.

LOPES, M. I. V. Telenovela: internacionalização e interculturalidade. SP: Loyola, 2004.

16 Para mais informações ver http://www.telaviva.com.br/22/07/2013/8k-e-evolucao-natural-da-radiodifusao-dizglobo/pt/348261/news.aspx Acesso em 09 de dez. de 2013. 
GOMES, I. M. M. Gênero televisivo como categoria cultural: um lugar no centro do mapa das mediações de Jesús Martín-Barbero. Revista FAMECOS (Impresso), v. 18, 2011.

MARTÍN-BARBERO, J. Dos meios às mediações. RJ: Editora da UFRJ, 2001.

MOTTER, M.L. Mecanismos de renovação do gênero telenovela: empréstimos e doações. In: LOPES, M. I. V. Telenovela: internacionalização e interculturalidade. SP: Loyola, 2004.

PUCCI JR. R. L. Inovações estilísticas na telenovela: A situação em Avenida Brasil. Revista FAMECOS Porto Alegre, v. 21, n. 2, p. 675-697, maio-ago. 2014.

Trabalho apresentado no GT Estudos de Televisão do XXII Encontro Anual da Compós, Universidade Federal da Bahia, junho de 2013, Salvador/BA. Disponível em: <http://www.compos. org.br/data/biblioteca_2079.pdf> acesso em 13 de out. de 2013.

REZENDE, R. A tecnologia e a transformação do dispositivo televisivo: produções sensórias no hibridismo realidade/ficção. Revista Brasileira de História da Mídia, v.1, n.2, jul/dez, 2012.

THOMPSON, K. Storytelling in Film and Television. Cambridge/Londres: Harvard University Press, 2003. 